\title{
Catalytic Synthesis of Substrate-Free, Aligned and Tailored High Aspect Ratio Multiwall Carbon Nanotubes in an Ultrasonic Atomization Head CVD Reactor
}

\author{
Fahad Ali Rabbani, ${ }^{1}$ Zuhair Omar Malaibari, ${ }^{1}$ Muataz Ali Atieh, ${ }^{2,3}$ and Ammar Jamie ${ }^{1}$ \\ ${ }^{1}$ Department of Chemical Engineering, King Fahd University of Petroleum and Minerals, P.O. Box 5050, Dhahran 31261, Saudi Arabia \\ ${ }^{2}$ Qatar Environment and Energy Research Institute, Qatar Foundation, P.O. Box 5825, Doha, Qatar \\ ${ }^{3}$ College of Science and Engineering, Hamad Bin Khalifa University, Qatar Foundation, P.O. Box 5825, Doha, Qatar
}

Correspondence should be addressed to Zuhair Omar Malaibari; zuhairom@kfupm.edu.sa

Received 16 November 2015; Revised 1 February 2016; Accepted 8 February 2016

Academic Editor: Stefano Bellucci

Copyright ( 2016 Fahad Ali Rabbani et al. This is an open access article distributed under the Creative Commons Attribution License, which permits unrestricted use, distribution, and reproduction in any medium, provided the original work is properly cited.

\begin{abstract}
Chemical vapor deposition (CVD) method has proven its benchmark, over other methods, for the production of different types of carbon nanotubes (CNT) on commercial and lab scale. In this study, an injection vertical CVD reactor fitted with an ultrasonic atomization head was used in a pilot-plant scale (height $274 \mathrm{~cm}$, radius $25 \mathrm{~cm}$ ) for semicontinuous production of multiwall carbon nanotubes (MWCNTs). p-Xylene was used as a hydrocarbon precursor in which ferrocene was dissolved and provided the cracking catalyst. Atomization of the feed solution resulted in full and even dispersion of the catalytic solution. This dispersion led to the production of high aspect ratio MWCNTs (ranging from 8,000 to 12,000) at $850^{\circ} \mathrm{C}$. Different experimental parameters affecting the quality and quantity of the produced CNTs were investigated. These included temperature, reaction time, and flow rate of the reaction and carrier gases. Different properties of the produced CNTs were characterized using SEM and TEM, while TGA was used to evaluate their purity. Specific surface area of selected samples was calculated by BET.
\end{abstract}

\section{Introduction}

Over the last decade, many studies have been conducted on the production of carbon nanotubes (CNT). Different routes and precursors have yielded a variety of carbon nanomaterials $[1,2]$. By tuning reaction parameters, one can produce single wall carbon nanotubes (SWCNTs) or multiwall carbon nanotubes (MWCNTs) [3]. CNTs have a wide range of applications due to their novel properties. Uses include food production, clothes, pharmaceuticals, electronics, sensors, purification [4], cleaning products [5], and improving the mechanical properties of other materials [6]. The convenient production and applications of CNTs on a large scale, however, have not been reported, apparently because of the challenges in production, purification, and dispersion [1]. CNTs are produced by unique and miscellaneous techniques, such as arc discharge, laser ablation, and chemical vapor deposition (CVD). However, among all methods, mass production of CNTs can be most easily achieved by CVD. This technique can be scaled up and is widely used as a commercial process [7-9].

Lower carbon molecules, when used with ferrocene as a catalyst in a CVD reactor, produce SWCNTs [10-12], whereas by using the same catalyst with higher carbon molecules (e.g., toluene, $\mathrm{p}$-xylene, or n-hexane) MWCNTs can be produced $[1,13,14]$. Iron $(\mathrm{Fe})$, cobalt $(\mathrm{Co})$, and nickel $(\mathrm{Ni})$ are well known efficient catalysts for CNTs synthesis in CVD reactors [15]. However, these metals cannot be used directly in the reactor. They first need to be prepared in the form of compounds or mixtures, where they decompose to generate active sites for the reactants. For example, Yang et al. (2014) produced MWCNTs using $\mathrm{CoMgO}$ and $\mathrm{CoMnMgO}$ catalyst compounds, when feeding methane as the carbon source in a horizontal CVD reactor [16]. These types of catalyst compounds are very efficient in some cases, but their preparation is time consuming and requires sophisticated techniques. 
Therefore, the use of such catalysts could be a challenging step in mass production to commercialize the process. The potential applications of aligned and high aspect ratio MWCNTs cover the areas of water purification [4], mechanical strength enhancer [6], electronic equipment [17], and thermal conductors $[18,19]$.

By selecting the appropriate catalyst-substrate pair, one can produce CNTs of different types, such as horizontally/ vertically aligned, short/long, and crystalline/amorphous structures [5, 13, 20]. Moreover, in most previous studies, CNTs were produced on a small area of substrate, which could be made of silica, alumina, zeolite, or quartz. These types of substrates limit the synthesis of CNTs [21-24]. Singh et al. (2003) reported that only $1.0 \mathrm{~g} / \mathrm{h}$ of CNTs could be obtained on a flat substrate of quartz plate [25]. Craddock and Weisenberger (2015) proposed a scheme in which walls of the reactor lead to substrate-free method for production of CNTs [14]. Thus, in this work a quartz wall of an injection vertical CVD (IVCVD) reactor has been used as a substrate-free system for CNT synthesis. Although commercial production of CNT is run in CVD fluidized bed reactors, these reactors require continuous control of critical parameters [26, 27]. In contrast, our vertical CVD system is superior as it does not require the control of any fluidization parameters. Another advantage of our proposed reactor is that because it does not require maintenance of a certain fluidization velocity, it can be operated at low pressures [28]. Barreiro et al. (2006) used HiPco process for production of SWCNTs by using ferrocene. But this process required a pressure of 5 bar for cracking of ferrocene [29].

This study was aimed at furthering the goal of commercializing high aspect ratio MWCNTs production by minimizing the gap between scientific research and industrial development. An injection vertical chemical vapor deposition reactor (IVCVD) is used, in which a cocurrent, downward feed stream is introduced from the top of the reactor along with $\mathrm{H}_{2}$ and $\mathrm{Ar}$ gases. p-Xylene (B.P. $138.5^{\circ} \mathrm{C}$ ) is used as a carbon source and ferrocene (B.P. $249^{\circ} \mathrm{C}$ ) as the catalyst.

Ferrocene is relatively safe and more economically feasible as compared to other organometallic catalytic compounds. It decomposes at a temperature of $600^{\circ} \mathrm{C}$ [30]. And if large scale CNTs production is required, ferrocene is preferred over other organometallic compounds such as nickelocene [31].

Different properties of produced CNTs, specifically diameters and aspect ratios, are not only governed by the precursor and catalyst combination. Other parameters, such as reaction temperature, hydrogen (reaction gas) composition, and reaction time also affect the properties of the produced CNTs [13]. In this study, the role of these parameters is investigated by characterizing produced MWCNTs using scanning electron microscopy (SEM), transmission electron microscopy (TEM), thermogravimetric analysis (TGA), and Brunauer, Emmett, and Teller (BET) analysis.

\section{Experimental}

2.1. The Injection Vertical CVD Reactor System. The experimental setup used to synthesize MWCNTs is shown in
Figure 1. The raw materials p-xylene $\left(\mathrm{C}_{8} \mathrm{H}_{10}, 96-99 \%\right.$ purity) and ferrocene $\left(\left(\mathrm{C}_{5} \mathrm{H}_{5}\right)_{2} \mathrm{Fe}, 96-99 \%\right.$ purity $)$ were purchased from Sigma-Aldrich Co. LLC and Honeywell Riedel-de Haen International Inc. and were used without further purification. Ultrasonic atomizer system $(20 \mathrm{kHz}$, type 6061 , and model WS20K50S316) was purchased from Sonaer Ultrasonics, New York. Hydrogen and argon gases were purchased from a local supplier.

The reactor was heated in an argon gas environment by using an electric furnace to obtain the required reaction temperature. A $1 \%$ wt. solution of ferrocene in p-xylene was prepared and transferred to a $50 \mathrm{~mL}$ syringe. The syringe was set on a syringe pump to inject feed solutions at different flow rates.

An ultrasonic atomization system (consisting of frequency generator, transducer, and spray nozzle) was installed at the top head of the vertical CVD reactor. The detailed parts of the wide spray atomizer nozzle are shown in Figure 2. The ultrasonic atomizer was operated at the maximum frequency of $20 \mathrm{kHz}$, to obtain the smallest possible droplet size. The feed solution passed through the wide spray atomizer nozzle and spread inside the reactor in an umbrella-shaped profile (Figure 3). The nozzle tip had a specific angle portion which made a wide range dispersion of droplets. This injection system created evenly distributed feed particles inside the quartz reactor. Up to our knowledge, this type of feed injection system was not used before for CNTs production on this scale. Previously this type of system was used for cracking of higher hydrocarbons to lower hydrocarbons [32].

Argon, the carrier gas (CG), took the atomized feed solution from the preheating zone to the reaction zone of the reactor. $\mathrm{H}_{2}$ was introduced into the reactor from the top when deposition of the feed solution on the quartz wall of reactor was observed. CNTs started forming due to thermal cracking of p-xylene and ferrocene and deposited on the wall of the vertical CVD reactor. The hydrogen gas was stopped after complete injection of the feed solution and the system was cooled down to room temperature in an Ar atmosphere. The synthesized CNTs were scrapped from the wall and collected from the bottom of the reactor.

2.2. Parameters Affecting the Properties of Produced CNTs. Three parameters that can affect the amount and properties of produced CNTs were investigated in this study: different flow rates of hydrogen gas, reaction temperature, and reaction time. A range of each parameter was chosen based on literature and our preliminary experiments as discussed in the Results and Discussion. Each parameter was varied keeping the other two parameters at mid values. Hydrogen flow rates ranged from 1 to $4 \mathrm{~L} / \mathrm{min}$, temperatures ranged from 750 to $950^{\circ} \mathrm{C}$, and reaction times ranged from 30 to $60 \mathrm{~min}$. After each run, the collected CNTs were weighed and the percentage yield for each run was calculated using fraction conversion as follows:

$$
\text { Yield }(\%)=\frac{W_{\mathrm{CNT}}}{W_{\text {pre }}} \times 100,
$$




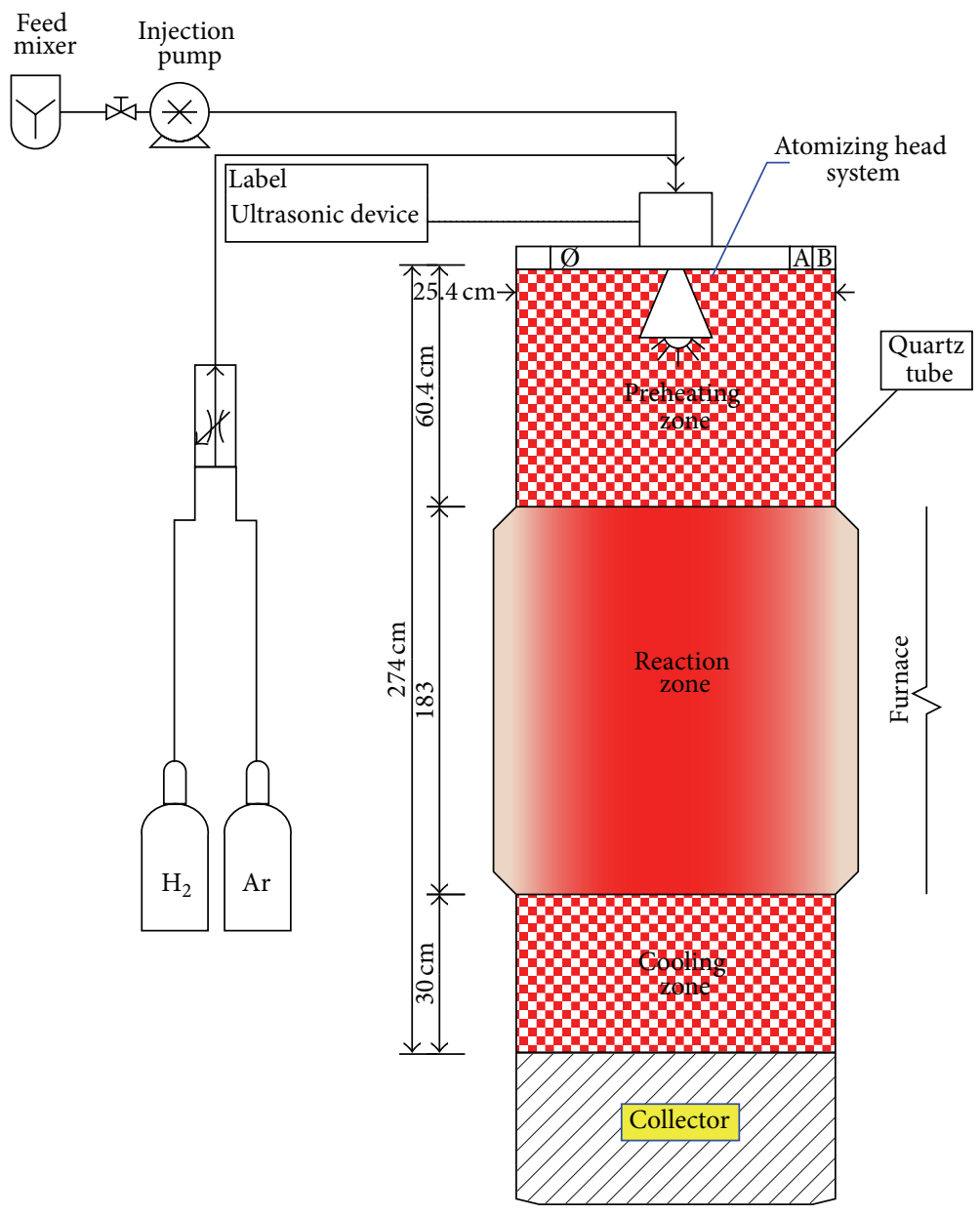

FIGURE 1: Injection vertical chemical vapor deposition reactor setup.

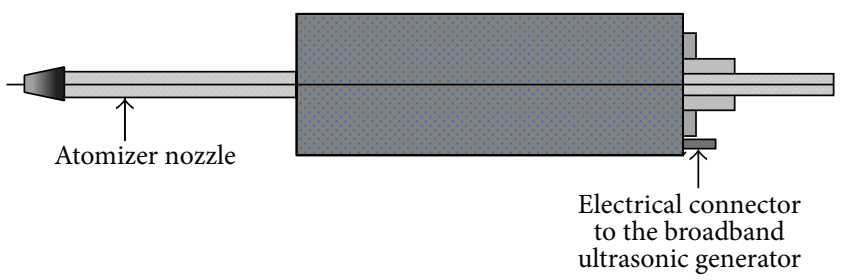

FIgURE 2: Conical wide range atomizing nozzle.

where $W_{\mathrm{CNT}}$ is the weight of MWCNTs obtained after each reaction and $W_{\text {pre }}$ is the weight of the precursor used to synthesize MWCNTs, which is p-xylene in our case.

2.3. Characterization of Produced CNTs. The synthesized MWCNTs were characterized by SEM, TEM, TGA, and BET. SEM analysis was performed using a field emission scanning electron microscope (TESCAN MIRA 3 FEG-SEM) which provided the structure and alignments of CNTs. Length of CNTs bundles and aspect ratios at different reaction conditions were also calculated based on the SEM analysis. TEM analysis was performed using a field emission electron microscope (JEM-2100F) which provided information about

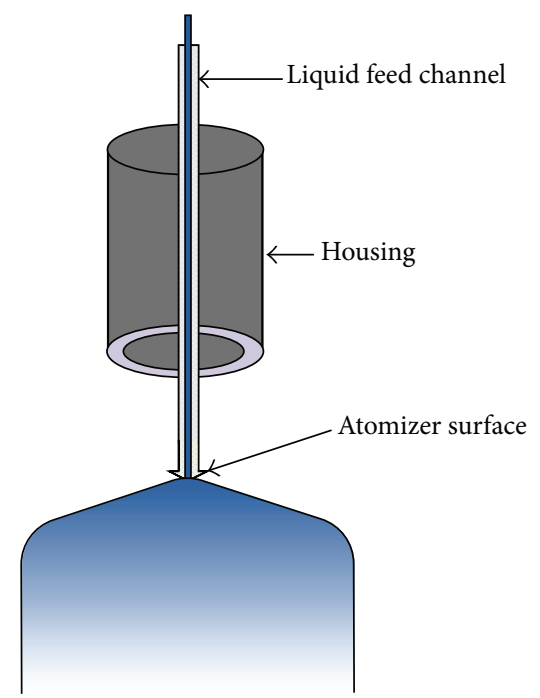

FIGURE 3: Velocity profile of feed solution from the atomizer nozzle.

single MWCNTs patterns, number of walls, space between walls, catalyst shape, and location of catalyst particles inside 


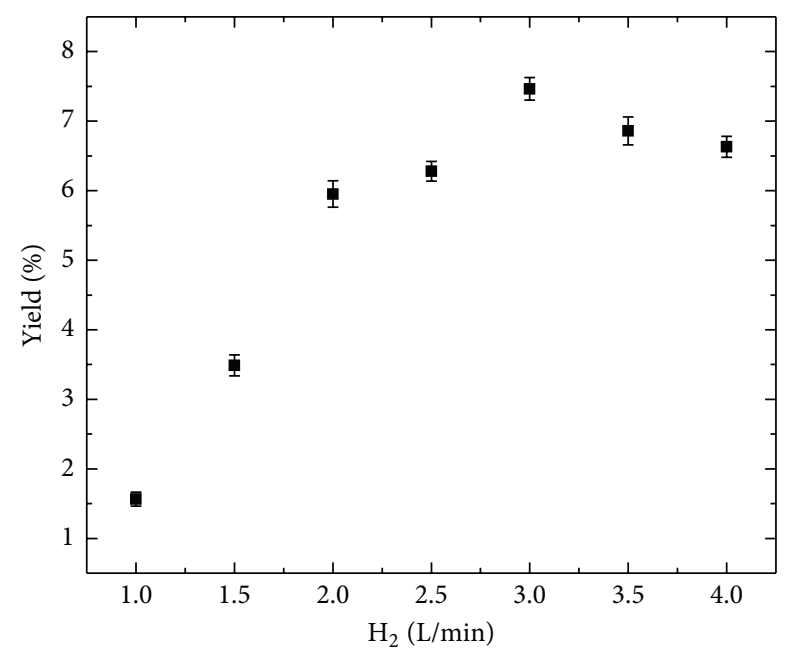

FIGURE 4: Yield of CNT obtained by varying flow rate of $\mathrm{H}_{2}$ and keeping constant temperature and reaction time at $850^{\circ} \mathrm{C}$ and $30 \mathrm{~min}$, respectively.

MWCNTs. Surface area of produced MWCNTs was measured by a surface area analyzer (Micromeritics, Norcross, GA, USA) in a Nitrogen atmosphere with a 15 -point BET at $77^{\circ} \mathrm{K}$.

A thermogravimetric analyzer (K.U. Leuven SDT, Q600) was used to evaluate the purity of produced CNTs. Purity of CNTs is described as the nonash content present in the sample of CNT. Nonash content in the samples is iron (catalyst) which can usually be removed by acid treatment. However, in this study we characterized as-synthesized MWCNTs to study unmodified properties of the product. In all TGA runs a $5 \mathrm{mg}$ sample was oxidized in air. The temperature was ranged from 50 to $750^{\circ} \mathrm{C}$ at a heating rate of $10^{\circ} \mathrm{C} / \mathrm{min}$ to cover the MWCNTs oxidation range.

\section{Results and Discussion}

3.1. Crucial Role of Reaction Gas $\left(\mathrm{H}_{2}\right)$. Figure 4 shows the data obtained by varying $\mathrm{H}_{2}$ and Ar flow rates in a way that the total flow rates of both gases will be kept at $4.0 \mathrm{~L} / \mathrm{min}$. Thus, increasing hydrogen flow rate will result in decreasing the argon flow rate. Temperature and reaction time of the system were kept constant at $850^{\circ} \mathrm{C}$ and $30 \mathrm{~min}$, respectively (determined from preliminary experiments and further confirmed in Sections 3.2 and 3.3). CNTs yield increases by increasing $\mathrm{H}_{2}$ flow rate until it reaches a maximum value of $7.4 \%$ at $3 \mathrm{~L} / \mathrm{min}$. A further increase in $\mathrm{H}_{2}$ flow rate does not materially affect the yield. Increase in yield from lower flow rates to higher flow rates is due to the reducing nature of $\mathrm{H}_{2}$.

p-Xylene $\left(\mathrm{C}_{8} \mathrm{H}_{10}\right)$ and ferrocene $\left(\mathrm{C}_{10} \mathrm{H}_{10} \mathrm{Fe}\right)$ crack to form atomic carbon and iron in the presence of a reducing agent. Hence the concentration of $\mathrm{H}_{2}$ in the reactor accelerates CNTs formation $[33,34]$. However, if the $\mathrm{H}_{2}$ concentration reaches to its saturation point, then further increase in $\mathrm{H}_{2}$ will result in the deceleration of CNTs formation.

In our system, the saturation of $\mathrm{H}_{2}$ was reached at $3.0 \mathrm{~L} /$ min and maximum yield was obtained at this point. Then further increase in hydrogen flow rate did not enhance the yield but rather it started decreasing. This is because, at higher concentrations, hydrogen started reacting with carbon to produce lower hydrocarbons which caused low yields of CNTs. It was observed from SEM images that although the yield decreased at $4.0 \mathrm{~L} / \mathrm{min}$ flow rate of $\mathrm{H}_{2}$ as compared to the yield at $3.0 \mathrm{~L} / \mathrm{min}$, well aligned and large bundles of carbon nanotubes were obtained at $4.0 \mathrm{~L} / \mathrm{min}$ that were not present at other conditions (Figure 5).

The raw MWCNTs samples that were obtained at higher $\mathrm{H}_{2}$ flow rates $(3,3.5$, and $4 \mathrm{~L} / \mathrm{min})$ were analyzed through thermogravimetric analysis (TGA). Results are shown in Figure 6. The figure shows a sharp decrease in weight loss of $\mathrm{CNTs}$ that occurred in the range $500-600^{\circ} \mathrm{C}$. Further increase in temperature removed all carbon from samples and about $4 \%$ residue remained after complete oxidation. This $96 \%$ pure MWCNTs could be attributed to the ideal ratio of ferrocene to p-xylene, and perfect dispersion of the feed solution into the reactor by using the ultrasonic atomized technology.

3.2. Optimizing the Reaction Temperature. Reaction temperature plays a very important role in CNTs morphology and yield, as it controls the catalyst particle size, which in turn controls the diameter and aspect ratio of produced CNTs. Ferrocene (the catalyst) is an organometallic compound which produces Fe particles by thermal cracking at $600^{\circ} \mathrm{C}$ [30]. After decomposition, Fe particles agglomerate due to intramolecular forces. In this study temperature was varied from 750 to $950^{\circ} \mathrm{C}$, which is higher than the decomposition temperature of ferrocene. Kinetic studies at atomic level illustrated the idea of diffusion by collision. This means that at high temperatures molecules will collide frequently to form larger particles than those formed at lower temperatures. Hence, the diameter of MWCNTs should increase at higher temperatures as described by different authors [30, 34, 35].

The reaction temperature was varied from 750 to $950^{\circ} \mathrm{C}$ while keeping all other conditions constant: flow rates of $\mathrm{H}_{2}$ and Ar at 3 and $1 \mathrm{~L} / \mathrm{min}$, respectively, and time of reaction at $30 \mathrm{~min}$. As shown in Figure 7 the yield increased from 2.3\% at $750^{\circ} \mathrm{C}$ to $7 \%$ at $850^{\circ} \mathrm{C}$. A further increase in temperature to $950^{\circ} \mathrm{C}$ decreased the yield to $5.8 \%$.

SEM analysis of produced MWCNTs indicated that, at $750^{\circ} \mathrm{C}, \mathrm{CNT}$ contained some unreacted particles (Figures 8 (a) and $8(\mathrm{~b}))$. These unreacted particles were not present when the temperature was raised to $850^{\circ} \mathrm{C}$ (Figures $8(\mathrm{c}$ ) and $8(\mathrm{~d})$ ), and clear aligned structure of MWCNTs appeared. At temperatures of $900^{\circ} \mathrm{C}$ and above, the alignment of MWCNTs bundles started disappearing and eventually at $950^{\circ} \mathrm{C}$ the aligned bundles converted to random tubes as shown in (Figures $8(\mathrm{e})$ and $8(f))$.

The diameters of MWCNTs, which were synthesized at different temperatures (i.e., 750, 800, 850, 900, and $950^{\circ} \mathrm{C}$ ), were measured by SEM at three different locations. The data obtained are shown in Figure 9.

Temperature plays an important role in controlling the shape and size of catalyst particles which eventually controls the diameter of CNTs [36]. The MWCNTs we synthesized showed that there was a large difference in the diameter range of MWCNTs at 750,800 , and $850^{\circ} \mathrm{C}$, and this range narrows 


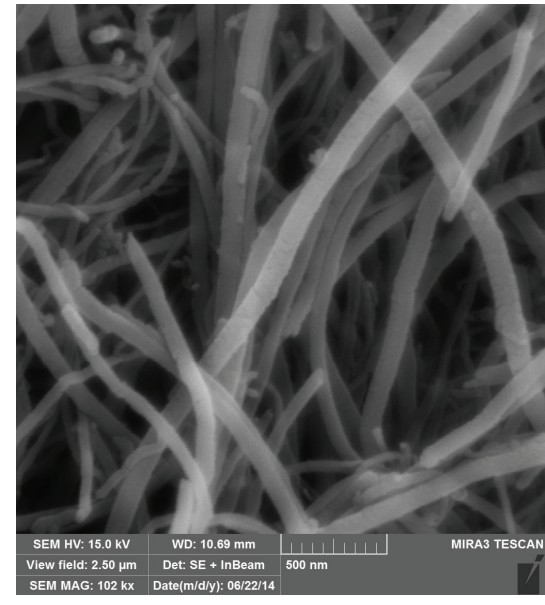

(a)

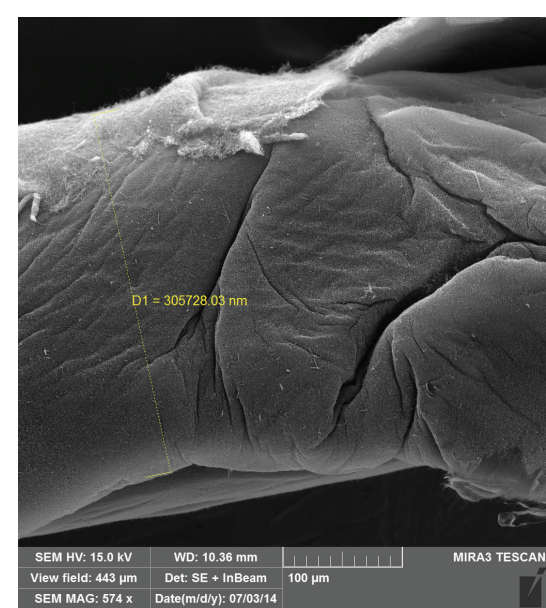

(b)

FIGURE 5: SEM image of MWCNTs obtained at $850^{\circ} \mathrm{C}$ temperature, $3.5 \mathrm{~L} / \mathrm{min}_{2}$ flow rate, $30 \mathrm{~min}$ feed reaction time; (a) resolution: $500 \mathrm{~nm}$, MAG: $95.4 \mathrm{kx},(\mathrm{b})$ resolution: $100 \mu \mathrm{m}, \mathrm{MAG}: 574 \mathrm{x}$.

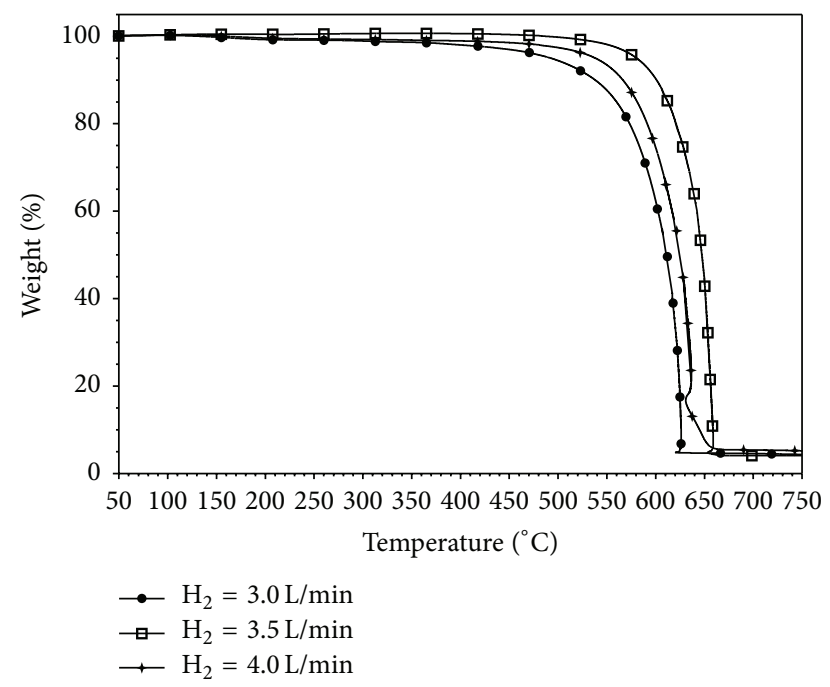

FigURE 6: TGA of raw MWCNTs obtained by changing hydrogen flow rates.

at 900 and $950^{\circ} \mathrm{C}$. Lee et al. (2001) [22] and Lee et al. (2002) [24] found the diameter of Fe particles at $850^{\circ} \mathrm{C}$ and $950^{\circ} \mathrm{C}$ as $90 \pm 20 \mathrm{~nm}$ and $150 \pm 40 \mathrm{~nm}$, respectively. However, we found that the diameters of MWCNTs which were synthesized at $850^{\circ} \mathrm{C}$ and $950^{\circ} \mathrm{C}$ were $55 \pm 15$ and $50 \pm 10 \mathrm{~nm}$, respectively. These results indicated that we obtained smaller diameter MWCNTs and hence smaller diameters of catalyst particles than those which were mentioned in literature. These small diameter MWCNTs which we synthesized resulted from the full dispersed feed solution particles inside the reactor.

TEM analysis was run for the sample which was obtained at $850^{\circ} \mathrm{C}$, where the highest yields of MWCNTs were obtained (Figure 10). Catalyst particles on the tip of the MWCNTs indicated that CNTs were formed due to a tip growth mechanism (Figure 10(a)). Multilayers of walls of carbon over catalyst particles are visible in Figure 10(b).

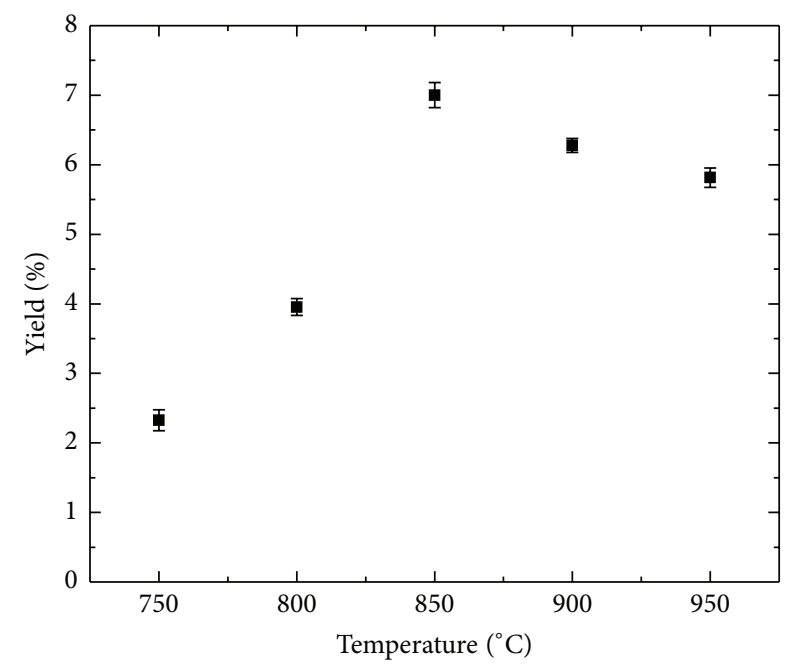

FIGURE 7: Yield of CNT obtained by varying reaction temperature and keeping a constant $\mathrm{H}_{2}$ flow rate and reaction time at $3 \mathrm{~L} / \mathrm{min}$ and $30 \mathrm{~min}$, respectively.

MWCNTs which were collected at various reaction temperatures were analyzed by TGA (Figure 11). The oxidation curves obtained for reaction temperatures between 750 and $900^{\circ} \mathrm{C}$ show similar weight loss trends. About $94 \pm 2 \%$ pure MWCNTs were recorded. Oxidation of these samples started at $500^{\circ} \mathrm{C}$ until all the carbon present in the samples burned out at $630^{\circ} \mathrm{C}$, leaving the residue behind (which is Fe in our case). However, the MWCNTs synthesized at high temperature $\left(950^{\circ} \mathrm{C}\right)$ exhibited a different oxidation trend. Purity analysis of this sample indicated that $25 \%$ impurity was present in the sample. Moreover, oxidation started at a lower temperature, $370^{\circ} \mathrm{C}$ as compared to $500^{\circ} \mathrm{C}$. As described earlier, at high temperature catalyst particles start to sinter and they lose their active sites which are necessary to form the CNTs. Therefore, these inactive catalyst particles, when 


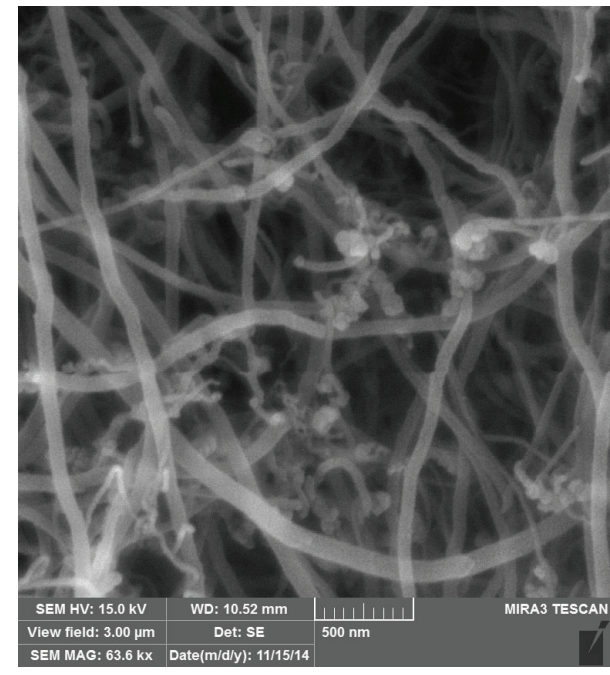

(a)

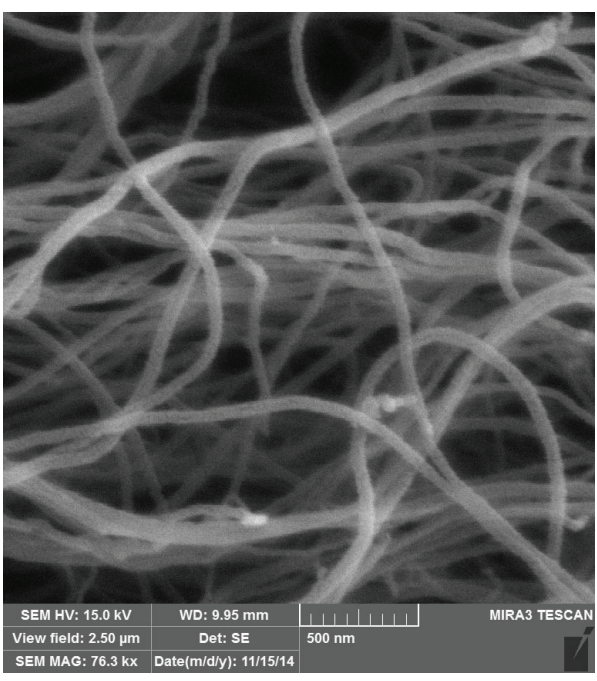

(c)

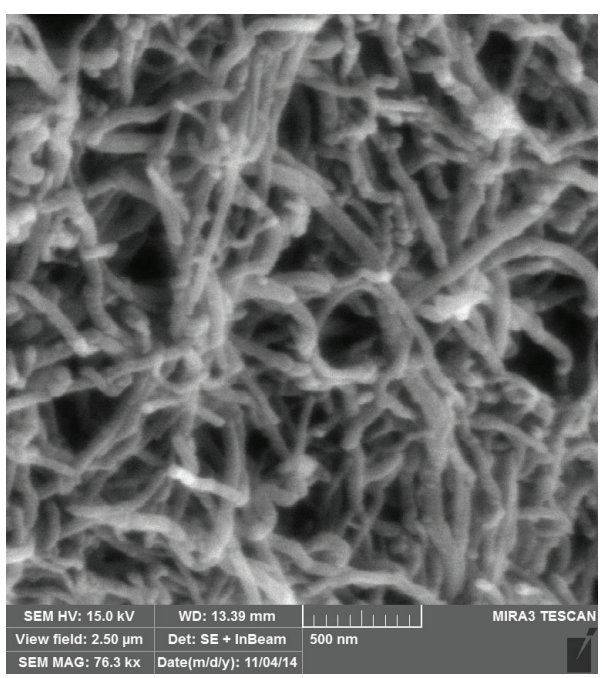

(e)

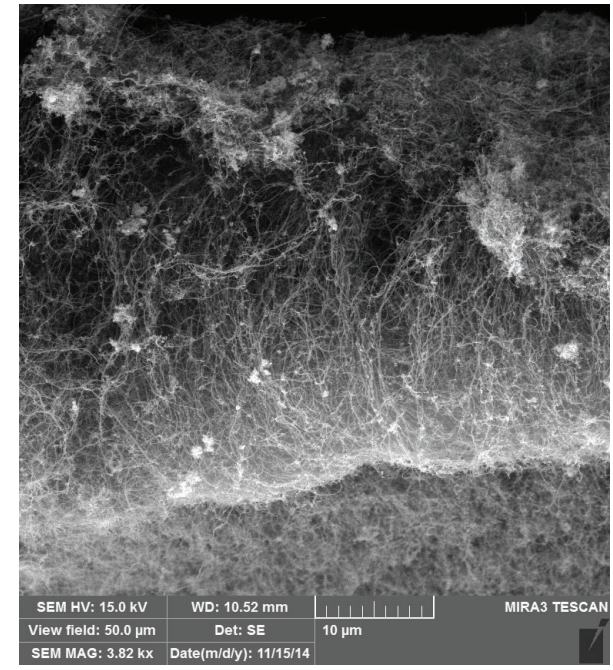

(b)

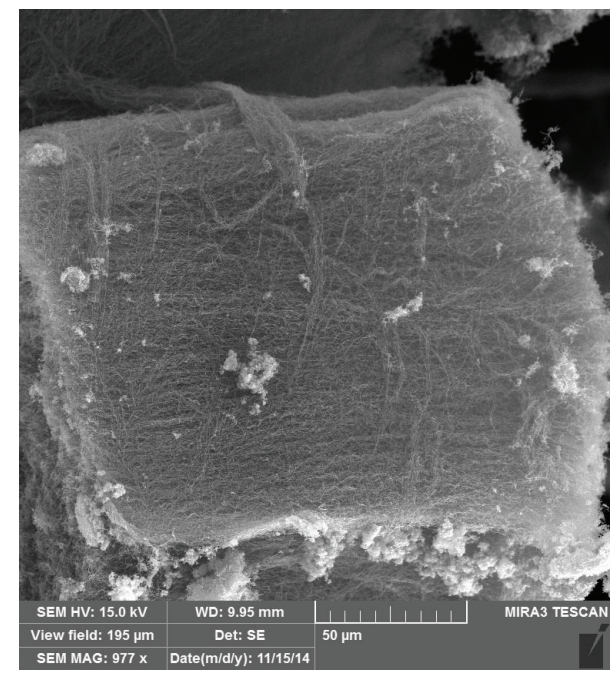

(d)

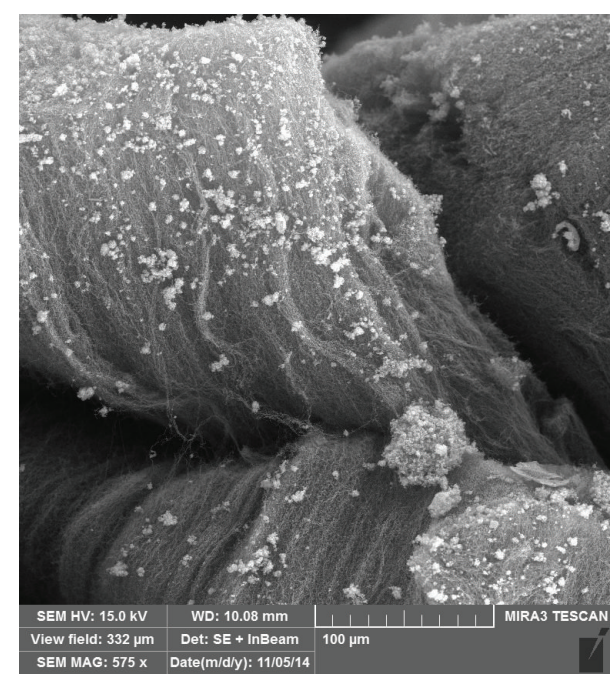

(f)

FIGURE 8: High and low resolution SEM images of MWCNTs obtained at different temperatures: (a and b) at $750^{\circ} \mathrm{C},\left(\mathrm{c}\right.$ and d) $850^{\circ} \mathrm{C}$, and (e and f) $950^{\circ} \mathrm{C}, 3 \mathrm{~L} / \mathrm{min}_{2}$ flow rate, $1 \mathrm{~L} / \mathrm{min}$ Ar flow rate, and reaction time of $30 \mathrm{~min}$. 


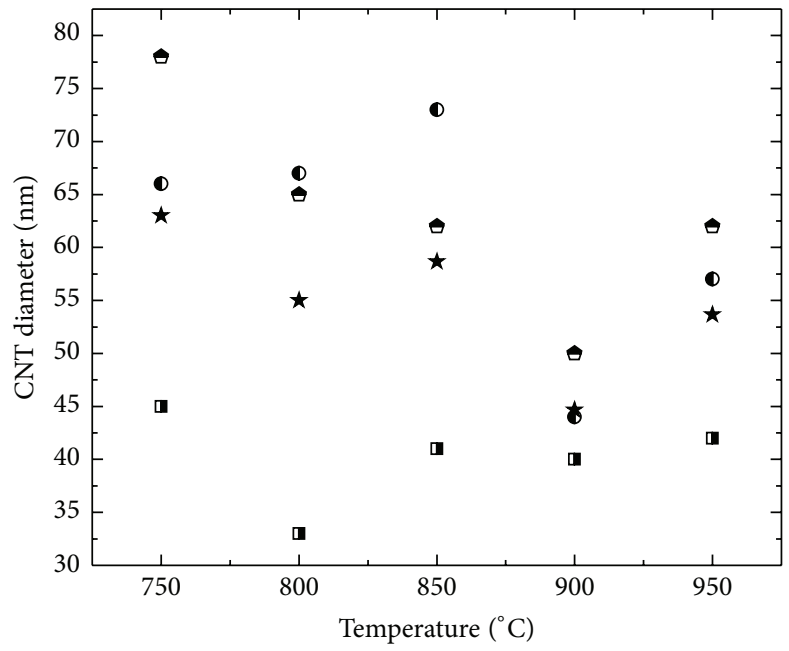

- Diameter CNT-1

- Diameter CNT-3

- Diameter CNT-2

$\star$ Average diameter

FIGURE 9: Diameters distribution of MWCNTs obtained from SEM images at various reaction temperatures.

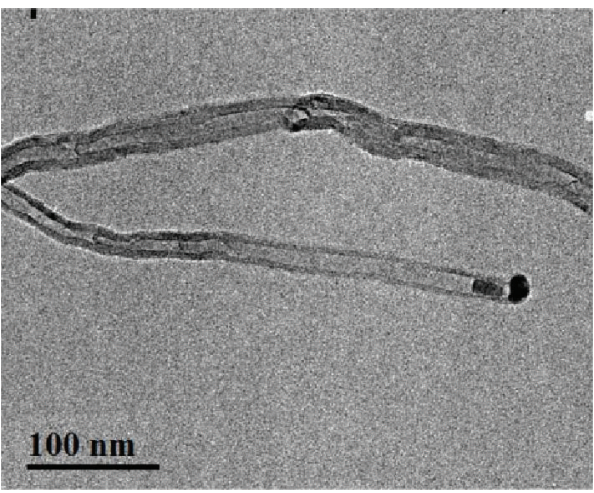

(a)

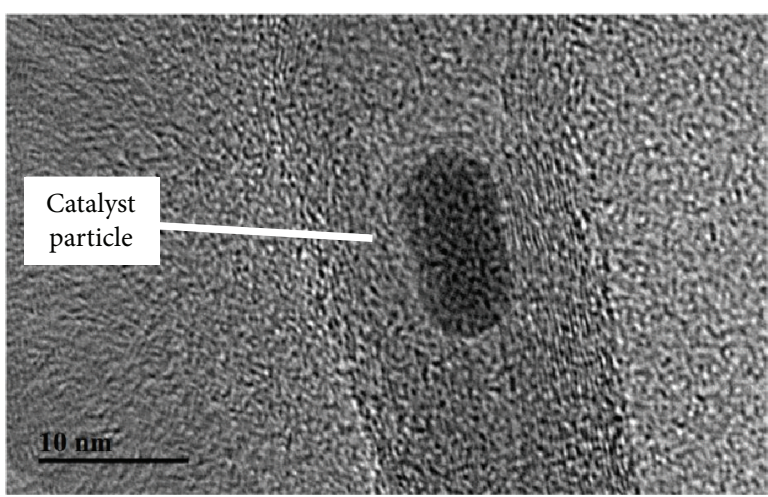

(b)

FIGURE 10: HRTEM image of one MWCNT: (a) complete tube, (b) shape of catalyst particle inside the MWCNT.

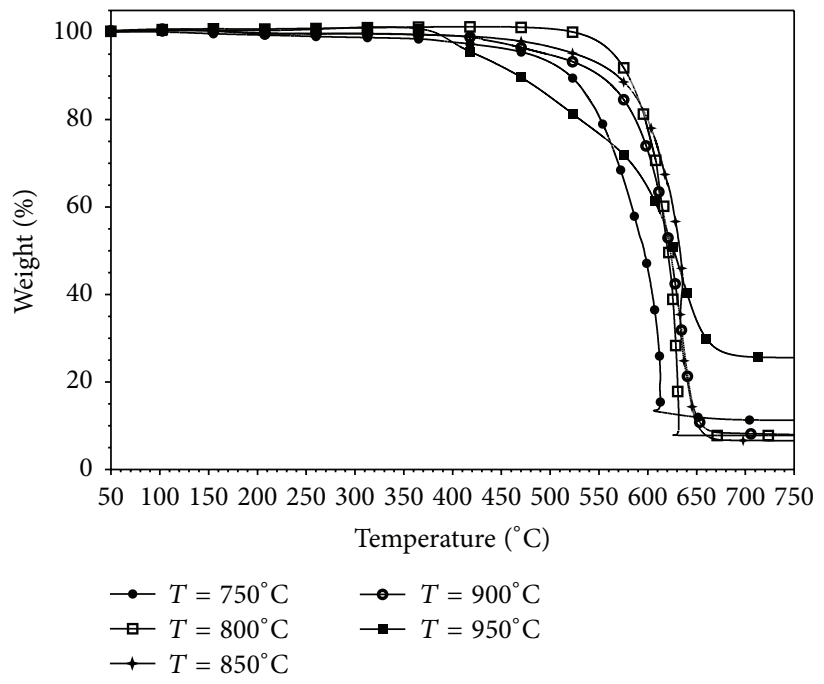

FIGURE 11: TGA of MWCNTs obtained by changing reaction temperature. 


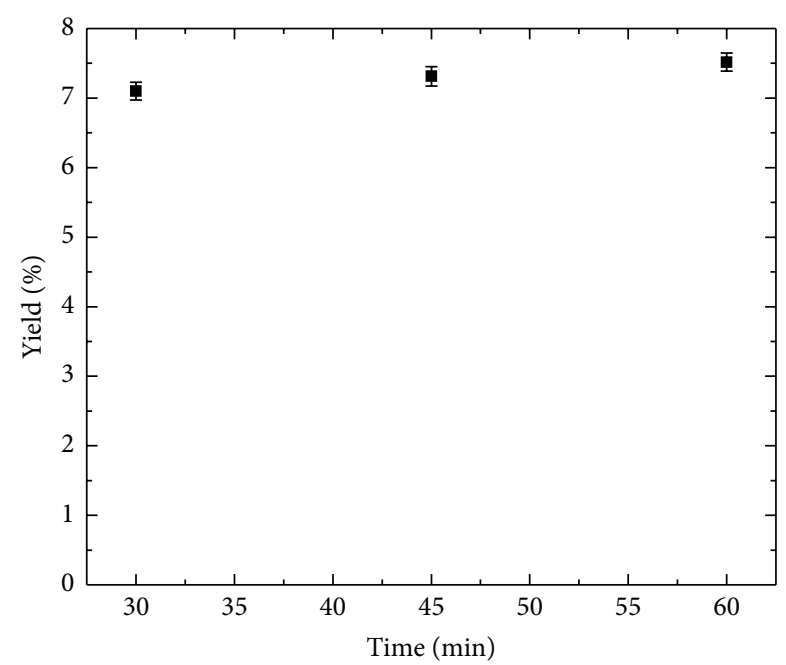

FIGURE 12: Yields of MWCNTs obtained by varying reaction time and keeping a constant temperature and $\mathrm{H}_{2}$ flow rate at $850^{\circ} \mathrm{C}$ and $4 \mathrm{~L} / \mathrm{min}$, respectively.

heated during TGA, absorbed heat and acted as an inside heating source for MWCNTs [36]. This phenomenon caused earlier oxidation of MWCNTs. The sintered and agglomerated particles can be seen in SEM images (Figures 8(e) and $8(\mathrm{f}))$.

3.3. Reaction Time Effect. A fixed amount of $50 \mathrm{~mL}$ of catalytic feed solution was injected in the quartz reactor through the atomizer and its flow rate was controlled by the syringe pump as shown in Figure 1. Therefore by selecting different appropriate flow rates, various reaction times were obtained. MWCNTs were synthesized at different reaction times 30,45 , and 60 minutes by keeping the reaction temperature constant at $850^{\circ} \mathrm{C}$, and flow rates of $\mathrm{H}_{2}$ and $\mathrm{Ar}$ gases at 3 and $1 \mathrm{~L} / \mathrm{min}$, respectively. The obtained yields were $7.1,7.3$, and $7.5 \%$ for 30 , 45, and $60 \mathrm{~min}$, respectively, as shown in Figure 12. It can be seen that, by increasing the reaction time, the yield increased somehow, but the increase was not so prominent that it could make a decisive difference in favor of selecting a higher reaction time as an optimum condition. In our vertical CVD reactor, an ultrasonic atomizing system was used which had a dual function, namely, to create the smallest possible droplet size of the feed solution without changing its composition and to disperse the feed solution evenly inside the reactor. Because of these two unique properties, when the reaction time of the feed solution was varied no significant changes in the MWCNTs yield were observed. This is in contrast to other CVD reactors, in which fluidized beds or floating catalyst techniques have been used and yields were affected by varying the reaction time [37].

Results obtained by TGA analysis of the MWCNTs produced from the three reaction times are shown in Figure 13. Complete oxidation of MWCNTs resulted in a weight loss of carbon. On the basis of the weight loss of the carbon content, we found that more than $96 \%$ pure MWCNTs were produced for all three reaction times, with no significant difference in purity between the three times. Therefore, it is logical to

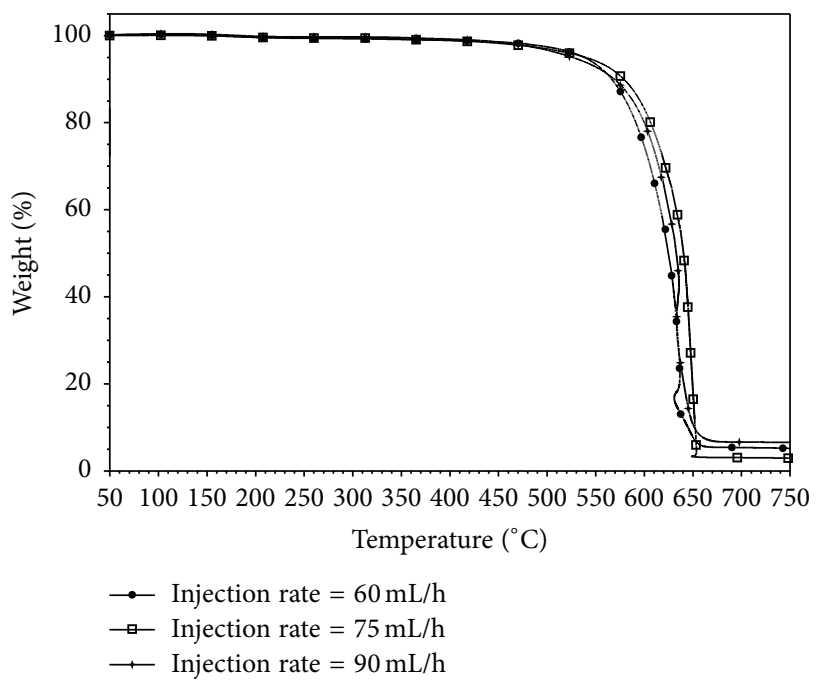

FIGURE 13: TGA of MWCNTs obtained by changing the feed reaction time.

select a minimum reaction time as an optimum condition for MWCNTs production.

3.4. General Features of Synthesized MWCNTs. The specific surface area (SSA) for different samples was calculated using multipoint BET analysis. The result indicated that SSA of MWCNTs varied between 50 and $90 \mathrm{~m}^{2} / \mathrm{g}$. High aspect ratio MWCNTs were obtained at $800^{\circ} \mathrm{C}$ and $850^{\circ} \mathrm{C}$ by using ferrocene and p-xylene. The $\mathrm{H}_{2}$ to Ar ratio was kept constant at $3: 1$. Under these conditions, the length of the produced flakes was found to vary between 150 and $238 \mu \mathrm{m}$ with a diameter range of 33-78 nm. Pint et al. (2008) [38] explained this phenomenon of "flying carpet flakes" formation. According to their study, $\mathrm{Fe}_{2} \mathrm{O}_{3}$ produces metallic iron in the reducing environment, such as $\mathrm{H}_{2}$, which is responsible for flake formation. In our work we used ferrocene for the Fe catalyst particles, which is more receptive to reduction in the presence of $\mathrm{H}_{2}$ than $\mathrm{Fe}_{2} \mathrm{O}_{3}$. We obtained very high aspect ratios (length/diameter) CNT flakes ranging from 8,000 to 12,000 (Figures 14(a) and 14(b)).

In order to investigate the effect of the reducing agent, we used only $\mathrm{H}_{2}$ at a high flow rate without any carrier gas (Ar), which was used in all previous experiments. In this way $\mathrm{H}_{2}$ behaved like a reducing agent as well as the carrier gas. CNTs obtained showed larger bundles of MWCNTs that were varying up to a few millimeters in length (Figure 14(c)). These types of aligned and large bundles of MWCNTs were not obtained in the previous experiments. Furthermore, aligned and large bundles of MWCNTs are preferred in those applications where high mechanical strength is required $[6$, 39].

\section{Conclusions}

Atomization of the feed solution to the CVD reactor using an ultrasonic atomizer produced an umbrella-shaped feed profile. This feed profile resulted in even dispersion of the 


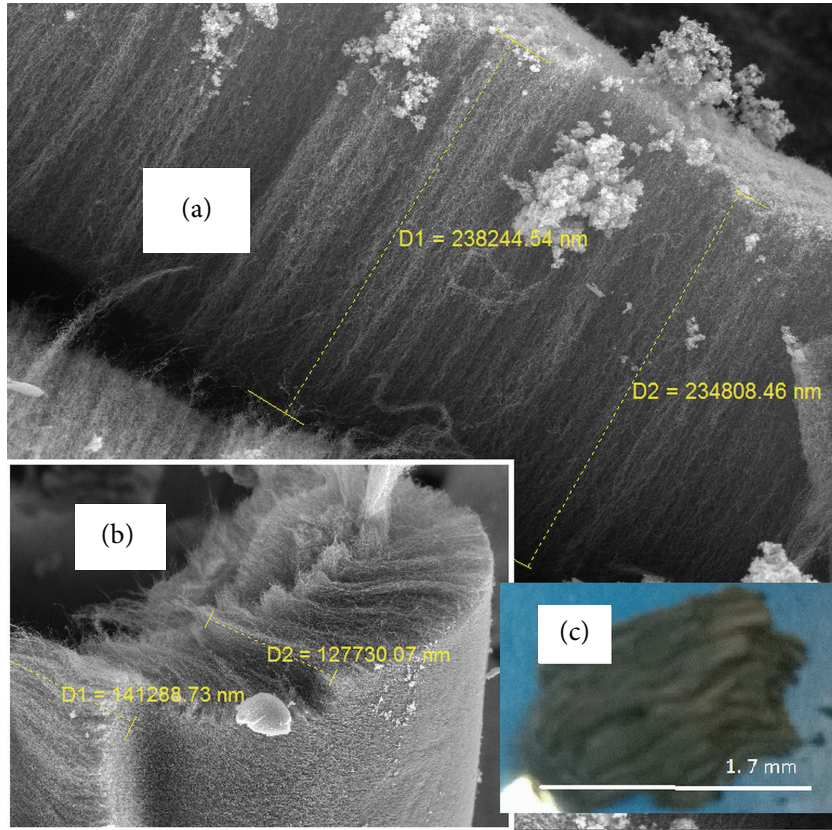

Figure 14: High aspect ratio MWCNTs synthesized at (a) SEM image at $\mathrm{H}_{2}$ and Ar flow rates 3 and $1 \mathrm{~L} / \mathrm{min}$, temperature $800^{\circ} \mathrm{C}$, and feed reaction time $30 \mathrm{~min}$, (b) SEM image at $\mathrm{H}_{2}$ and Ar flow rates 3 and $1 \mathrm{~L} / \mathrm{min}$, temperature $850^{\circ} \mathrm{C}$, and feed reaction time $30 \mathrm{~min}$, and (c) pure $\mathrm{H}_{2}$ flow rate $4 \mathrm{~L} / \mathrm{min}$ with no carrier gas, temperature $850^{\circ} \mathrm{C}$, and reaction time $30 \mathrm{~min}$.

feed solution and better utilization of the catalyst. This led to the production of high purity (96\%) free ash MWCNTs with catalyst particles oriented at the tip of produced MWCNTs as observed from TEM images. High yields were obtained at an optimized temperature of $850^{\circ} \mathrm{C}$ resulting in MWCNTs with aspect ratios up to 12,000 . Increasing the reducing agent $\left(\mathrm{H}_{2}\right)$ flow rate increased the yield, while using pure $\mathrm{H}_{2}$ resulted in high length MWCNTs bundles up to $1.7 \mathrm{~mm}$. Changing the reaction time did not have a pronounced effect on the yield or purity of the produced CNTs. The study presented a CVD reactor system that can be easily controlled to produce MWCNTs with a wide range of properties compared to fluidized beds or floating catalyst techniques that are relatively difficult to control. The introduced system could be an initial stage in mass production of customized MWCNTs for specified applications such as those requiring special mechanical properties.

\section{Conflict of Interests}

The authors declare that there is no conflict of interests regarding the publication of this paper.

\section{Acknowledgments}

The authors would like to acknowledge the support provided by the Deanship of Scientific Research at King Fahd University of Petroleum and Minerals (KFUPM) under Research Grant no. JF121010. The authors would also like to thank the Department of Chemical Engineering and the Center of Research Excellence in Nanotechnology at the university for their technical support.

\section{References}

[1] N. M. Mubarak, E. C. Abdullah, N. S. Jayakumar, and J. N. Sahu, "An overview on methods for the production of carbon nanotubes," Journal of Industrial and Engineering Chemistry, vol. 20, no. 4, pp. 1186-1197, 2014.

[2] H. Golnabi, "Carbon nanotube research developments in terms of published papers and patents, synthesis and production," Scientia Iranica, vol. 19, no. 6, pp. 2012-2022, 2012.

[3] A. Shaikjee and N. J. Coville, "The role of the hydrocarbon source on the growth of carbon materials," Carbon, vol. 50, no. 10, pp. 3376-3398, 2012.

[4] M. A. Atieh, O. Y. Bakather, B. S. Tawabini et al., "Removal of chromium (III) from water by using modified and nonmodified carbon nanotubes," Journal of Nanomaterials, vol. 2010, Article ID 232378, 9 pages, 2010.

[5] M. Endo, T. Hayashi, Y. A. Kim, M. Terrones, and M. S. Dresselhaus, "Applications of carbon nanotubes in the twenty-first century," Philosophical Transactions of the Royal Society A: Mathematical, Physical and Engineering Sciences, vol. 362, no. 1823, pp. 2223-2238, 2004.

[6] K. Mezghani, M. Farooqui, S. Furquan, and M. Atieh, "Influence of carbon nanotube (CNT) on the mechanical properties of LLDPE/CNT nanocomposite fibers," Materials Letters, vol. 65, no. 23-24, pp. 3633-3635, 2011.

[7] M. Paradise and T. Goswami, "Carbon nanotubes-production and industrial applications," Materials and Design, vol. 28, no. 5, pp. 1477-1489, 2007.

[8] P. M. Ajayan, "Nanotubes from carbon," Chemical Reviews, vol. 99, no. 7, pp. 1787-1800, 1999.

[9] A. G. Mamalis, L. O. G. Vogtländer, and A. Markopoulos, "Nanotechnology and nanostructured materials: trends in carbon nanotubes," Precision Engineering, vol. 28, no. 1, pp. 16-30, 2004.

[10] H. M. Cheng, F. Li, G. Su et al., "Large-scale and low-cost synthesis of single-walled carbon nanotubes by the catalytic pyrolysis of hydrocarbons," Applied Physics Letters, vol. 72, no. 25, pp. 3282-3284, 1998.

[11] O. Smiljanic, B. L. Stansfield, J.-P. Dodelet, A. Serventi, and S. Désilets, "Gas-phase synthesis of SWNT by an atmospheric pressure plasma jet," Chemical Physics Letters, vol. 356, no. 3-4, pp. 189-193, 2002.

[12] L. F. Su, J. N. Wang, F. Yu, Z. M. Sheng, H. Chang, and C. Pak, "Continuous production of single-wall carbon nanotubes by spray pyrolysis of alcohol with dissolved ferrocene," Chemical Physics Letters, vol. 420, no. 4-6, pp. 421-425, 2006.

[13] Q. Zhang, J.-Q. Huang, M.-Q. Zhao, W.-Z. Qian, and F. Wei, "Carbon nanotube mass production: principles and processes," ChemSusChem, vol. 4, no. 7, pp. 864-889, 2011.

[14] J. D. Craddock and M. C. Weisenberger, "Harvesting of large, substrate-free sheets of vertically aligned multiwall carbon nanotube arrays," Carbon, vol. 81, no. 1, pp. 839-841, 2015.

[15] F. Wei, Q. Zhang, W.-Z. Qian et al., "The mass production of carbon nanotubes using a nano-agglomerate fluidized bed reactor: a multiscale space-time analysis," Powder Technology, vol. 183, no. 1, pp. 10-20, 2008.

[16] W. Yang, Y.-Y. Feng, C.-F. Jiang, and W. Chu, "Synthesis of multi-walled carbon nanotubes using $\mathrm{CoMnMgO}$ catalysts 
through catalytic chemical vapor deposition," Chinese Physics B, vol. 23, no. 12, pp. 128-201, 2014.

[17] S. Ravindran, S. Chaudhary, B. Colburn, M. Ozkan, and C. S. Ozkan, "Covalent coupling of quantum dots to multiwalled carbon nanotubes for electronic device applications," Nano Letters, vol. 3, no. 4, pp. 447-453, 2003.

[18] J. Che, T. Çagin, and W. A. Goddard III, "Thermal conductivity of carbon nanotubes," Nanotechnology, vol. 11, no. 2, pp. 65-69, 2000.

[19] R. Andrews, D. Jacques, D. Qian, and T. Rantell, "Multiwall carbon nanotubes: synthesis and application," Accounts of Chemical Research, vol. 35, no. 12, pp. 1008-1017, 2002.

[20] Y. S. Park, H. S. Moon, M. Huh et al., "Synthesis of aligned and length-controlled carbon nanotubes by chemical vapor deposition," Carbon Letters, vol. 14, no. 2, pp. 99-104, 2013.

[21] B. C. Satishkumar, A. Govindaraj, and C. N. R. Rao, "Bundles of aligned carbon nanotubes obtained by the pyrolysis of ferrocene-hydrocarbon mixtures: role of the metal nanoparticles produced in situ," Chemical Physics Letters, vol. 307, no. 3-4, pp. 158-162, 1999.

[22] C. J. Lee, J. Park, Y. Huh, and J. Y. Lee, “Temperature effect on the growth of carbon nanotubes using thermal chemical vapor deposition," Chemical Physics Letters, vol. 343, no. 1-2, pp. 33-38, 2001.

[23] R. Andrews, D. Jacques, A. M. Rao et al., "Continuous production of aligned carbon nanotubes: a step closer to commercial realization," Chemical Physics Letters, vol. 303, no. 5-6, pp. 467474, 1999.

[24] C. J. Lee, J. Park, and J. A. Yu, "Catalyst effect on carbon nanotubes synthesized by thermal chemical vapor deposition," Chemical Physics Letters, vol. 360, no. 3-4, pp. 250-255, 2002.

[25] C. Singh, M. S. P. Shaffer, K. K. K. Koziol, I. A. Kinloch, and A. H. Windle, "Towards the production of large-scale aligned carbon nanotubes," Chemical Physics Letters, vol. 372, no. 5-6, pp. 860-865, 2003.

[26] Q. Weizhong, L. Tang, W. Zhanwen et al., "Production of hydrogen and carbon nanotubes from methane decomposition in a two-stage fluidized bed reactor," Applied Catalysis A: General, vol. 260, no. 2, pp. 223-228, 2004.

[27] Y.-W. Yen, M.-D. Huang, and F.-J. Lin, "Synthesize carbon nanotubes by a novel method using chemical vapor depositionfluidized bed reactor from solid-stated polymers," Diamond and Related Materials, vol. 17, no. 4-5, pp. 567-570, 2008.

[28] Q. Zhang, M.-Q. Zhao, J.-Q. Huang et al., "Vertically aligned carbon nanotube arrays grown on a lamellar catalyst by fluidized bed catalytic chemical vapor deposition," Carbon, vol. 47, no. 11, pp. 2600-2610, 2009.

[29] A. Barreiro, S. Hampel, M. H. Rümmeli et al., "Thermal decomposition of ferrocene as a method for production of singlewalled carbon nanotubes without additional carbon sources," Journal of Physical Chemistry B, vol. 110, no. 42, pp. 2097320977, 2006.

[30] N. Koprinarov, M. Konstantinova, T. Ruskov, and I. Spirov, "Ferromagnetic nanomaterials obtained by thermal decomposition of ferrocene in a closed chamber," Bulgarian Journal of Physics, vol. 34, pp. 17-32, 2007.

[31] R. Sen, A. Govindaraj, and C. N. R. Rao, "Carbon nanotubes by the metallocene route," Chemical Physics Letters, vol. 267, no. 3-4, pp. 276-280, 1997.

[32] J. M. Meacham, M. J. Varady, D. Esposito, F. L. Degertekin, and A. G. Fedorov, "Micromachined ultrasonic atomizer for liquid fuels," Atomization and Sprays, vol. 18, no. 2, pp. 163-190, 2008.
[33] A. Rashidi, R. Lotfi, E. Fakhrmosavi, and M. Zare, "Production of single-walled carbon nanotubes from methane over Co-Mo/ $\mathrm{MgO}$ nanocatalyst: a comparative study of fixed and fluidized bed reactors," Journal of Natural Gas Chemistry, vol. 20, no. 4, pp. 372-376, 2011.

[34] C. Singh, M. S. P. Shaffer, and A. H. Windle, "Production of controlled architectures of aligned carbon nanotubes by an injection chemical vapour deposition method," Carbon, vol. 41, no. 2, pp. 359-368, 2003.

[35] L. Tapasztó, K. Kertész, Z. Vértesy et al., "Diameter and morphology dependence on experimental conditions of carbon nanotube arrays grown by spray pyrolysis," Carbon, vol. 43 , no. 5 , pp. 970-977, 2005.

[36] A. A. Muataz, F. Ahmadun, C. Guan, E. Mahdi, and A. Rinaldi, "Effect of reaction temperature on the production of carbon nanotubes," Nano, vol. 1, no. 3, pp. 251-257, 2006.

[37] D. Venegoni, P. Serp, R. Feurer, Y. Kihn, C. Vahlas, and P. Kalck, "Parametric study for the growth of carbon nanotubes by catalytic chemical vapor deposition in a fluidized bed reactor," Carbon, vol. 40, no. 10, pp. 1799-1807, 2002.

[38] C. L. Pint, S. T. Pheasant, M. Pasquali, K. E. Coulter, H. K. Schmidt, and R. H. Hauge, "Synthesis of high aspect-ratio carbon nanotube 'flying carpets' from nanostructured flake substrates," Nano Letters, vol. 8, no. 7, pp. 1879-1883, 2008.

[39] M. A. Atieh, N. Girun, E.-S. Mahdi et al., "Effect of multi-wall carbon nanotubes on the mechanical properties of natural rubber," Fullerenes Nanotubes and Carbon Nanostructures, vol. 14, no. 4, pp. 641-649, 2006. 

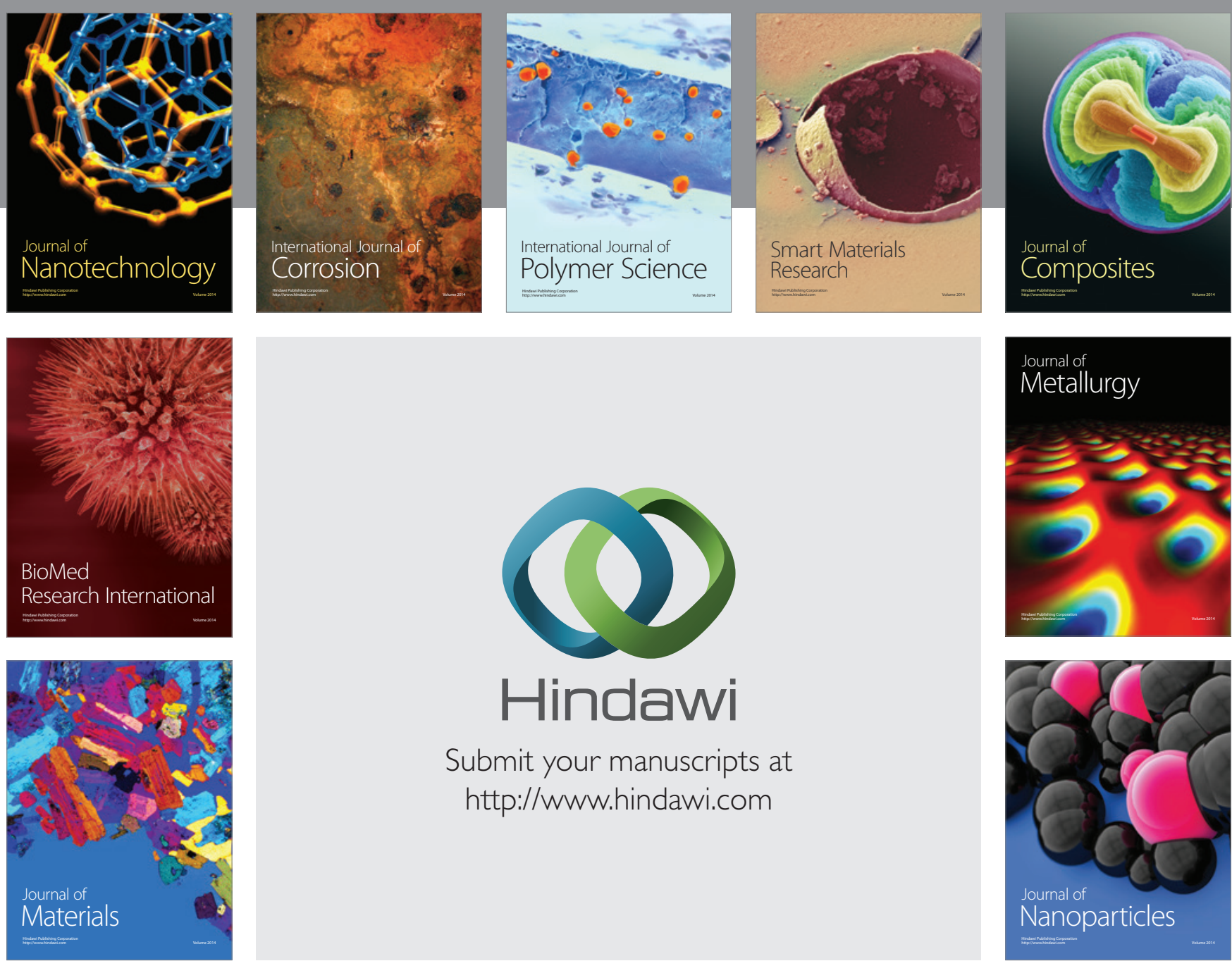

\section{Hindawi}

Submit your manuscripts at

http://www.hindawi.com

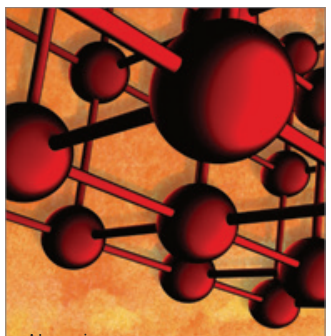

Materials Science and Engineering
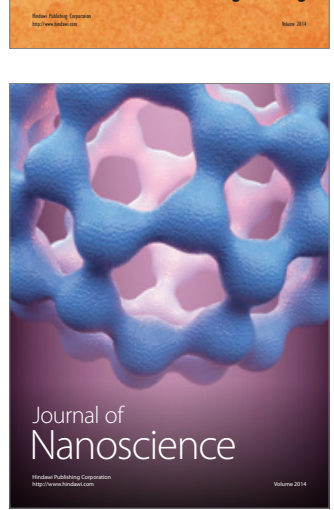
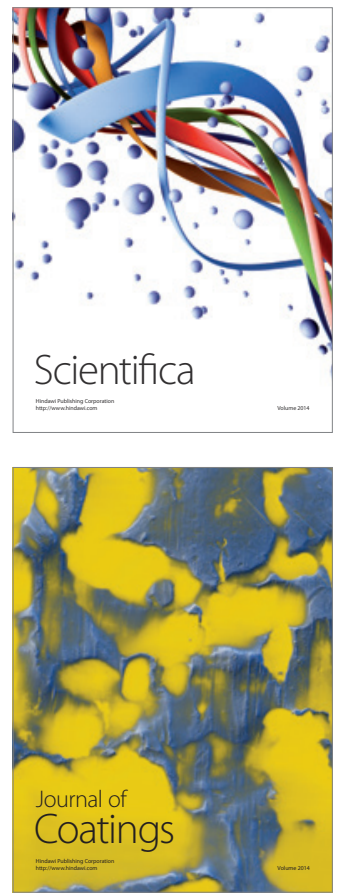
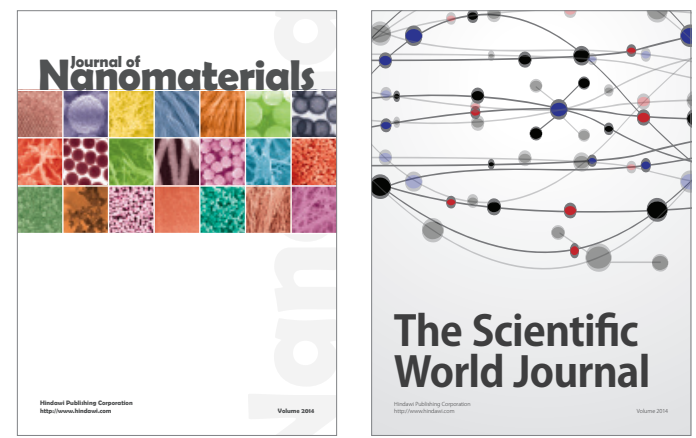

The Scientific World Journal
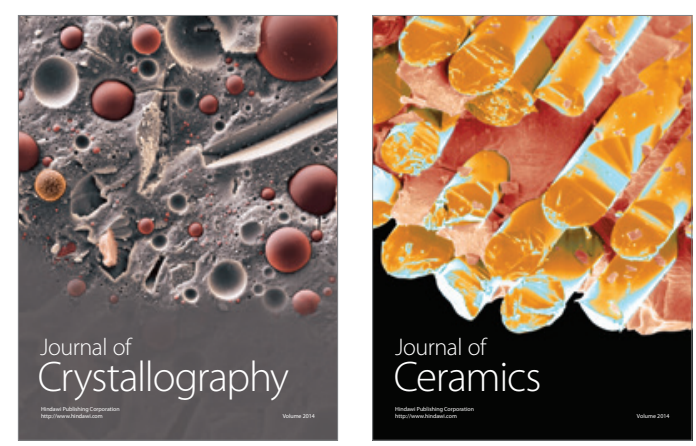
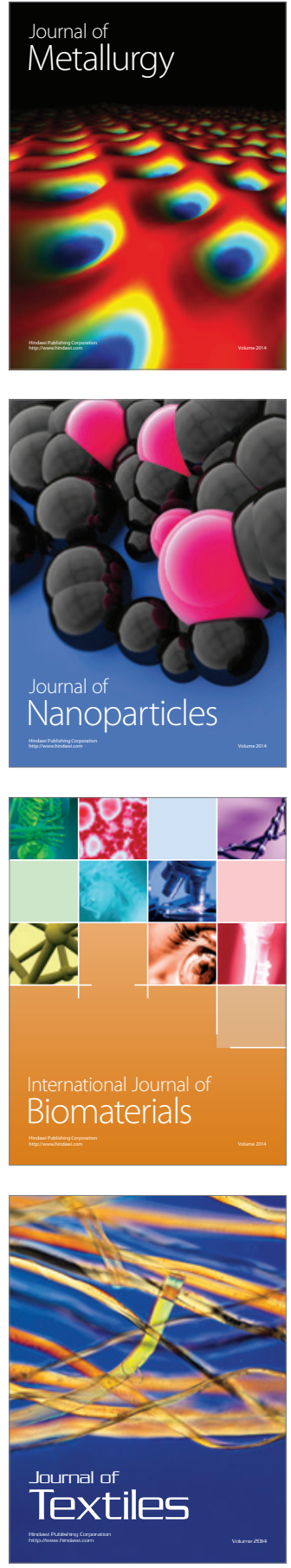